\title{
Clinical Reasoning: Persistent respiratory failure following cardiac arrest
}

Timothy Fullam, MD,* and John H. Sladky, MD*

Neurology ${ }^{\circledR}$ 2018;90:e2174-e2178. doi:10.1212/WNL.0000000000005688

\author{
Correspondence \\ Capt. Fullam \\ timothy.r.fullam.mil@ \\ mail.mil
}

\section{Section 1}

A 49-year-old woman was found unresponsive in bed, with ventricular fibrillation ultimately diagnosed. She was intubated and cardiac life support administered. Amiodarone was loaded and maintenance initiated. Left heart catheterization/ventriculography demonstrated no coronary artery disease, with reduced ejection fraction (EF)/global hypokinesis and dilated left ventricle. Intermittent ventricular tachycardia continued, causing recurrent arrests and metabolic acidosis. She was transitioned to extracorporeal membrane oxygenation (ECMO) with improved arrhythmias and acidosis but continued cardiogenic shock. She was transferred to an outside hospital for potential left ventricular assist device (LVAD) or cardiac transplant.

Hemodynamic stability and cardiac function improved from EF of $10 \%-15 \%$ to $40 \%-50 \%$ after 8 days of ECMO. The patient was treated with intermittent cisatracurium, dexmedetomidine, and fentanyl. ECMO was discontinued and she was transferred back to our hospital given no further need for LVAD or transplant. Due to persistent flaccid paralysis and failure to wean from the ventilator, neurology was consulted. She had been in the intensive care unit and intubated since presentation 10 days prior. Sedation had been held for 24 hours and she last received neuromuscular blockade 48 hours prior.

On initial examination, the patient remained intubated and unable to follow commands but would occasionally attend to examiners. Cranial nerves demonstrated equally reactive pupils with intact blink to threat and extraocular movements. She had bilateral ptosis and inability to fully close her eyes. Temporal wasting was present bilaterally with intact corneal reflexes and cough to deep suction. There was no volitional movement of her extremities except withdrawal of legs to noxious stimuli. Tone was flaccid and bulk generally decreased without focal areas of muscle atrophy/hypertrophy. Reflexes were 2 - in bilateral upper extremities but absent at the lower extremities with downgoing toes. There was trace percussion myotonia of the left thenar eminence. The remainder of the examination was unremarkable or unable to be performed.

\section{Question for consideration:}

1. What are potential etiologies for the patient's persistent respiratory failure?

\section{GO TO SECTION 2}




\section{Section 2}

Initially, there was concern for possible undiagnosed anoxic injury, nonconvulsive status epilepticus, or osmotic demyelination syndrome given the patient's cardiac arrest history and ECMO. Her elevated rapid shallow breathing index above 105 and apparent diffuse weakness raised concern for potential neuromuscular etiology of respiratory failure such as critical illness neuropathy/myopathy, acute inflammatory demyelinating polyradiculoneuropathy (AIDP), persistent neuromuscular blockade, undiagnosed autoimmune neuromuscular disorder, an inherited myopathy, or late-onset Pompe disease. ${ }^{1}$

Vitals were remarkable for fever of $38.4^{\circ} \mathrm{C}$ despite antibiotic therapy for ventilator-associated pneumonia. Basic laboratory studies, CSF analysis, and blood/urine cultures were unremarkable. EEG was without epileptiform abnormalities and MRI brain did not reveal any acute pathology.

Bedside EMG demonstrated reduced amplitudes of the left median and ulnar motor studies (2.4 and $3.2 \mathrm{mV}$, respectively). Distal latencies, conduction velocities, and F-waves latencies of median and ulnar nerves were normal. Left peroneal-tibialis anterior (TA) motor study was normal. Sensory studies and repetitive nerve stimulation were normal. Increased spontaneous activity was noted in the left TA, abductor pollicis brevis (APB), and first dorsal interosseous (FDI) with fibrillation potentials noted in the FDI and APB. There were no myotonic discharges or complex repetitive discharges. Motor units were only assessed in the left TA during brief withdrawal to pain, which were short duration, polyphasic, and low amplitude. Recruitment could not be accurately assessed given the patient's mental status.

The patient's husband reported that she had bilateral cataract surgery 1 year prior but denied any other diagnosis/ symptoms except daytime fatigue. They had 3 healthy children without any miscarriages. He denied family members with cardiac arrhythmias or early death. She was one of 4 living siblings and one sister also had early cataracts.

\section{Questions for consideration:}

1. What neuromuscular etiologies for respiratory failure are less likely based on the above?

2. Should any preexisting condition be considered?

GO TO SECTION 3 


\section{Section 3}

The normal F-wave latencies and normal CSF protein lowered concern for AIDP. Adult Pompe disease typically shows progressive respiratory compromise, elevated creatine kinase, and paraspinal myotonic discharges, and spares the heart clinically (although cardiac arrhythmias have been reported). Normal repetitive nerve stimulation made persistent neuromuscular blockade and myasthenia gravis unlikely. Lambert-Eaton myasthenic syndrome was also less likely given the repetitive nerve findings and presence of respiratory failure. Normal sensory responses argued against critical illness polyneuropathy. Compound motor action potentials (CMAP) in 2 separate nerves less than $80 \%$ the lower limit, denervation potentials detected on EMG, and short duration, low amplitude motor units in the TA were suspicious for a critical illness myopathy. As recruitment could not be accurately assessed given the patient's mental status, the motor units could not be definitively classified as myopathic. Direct muscle stimulation was not performed but has been used to distinguish critical illness myopathy from critical illness polyneuropathy.
Given the percussion myotonia, distal muscular atrophy, temporal wasting, bilateral ptosis, and cardiac arrhythmia/ cardiomyopathy of undetermined etiology, there was clinical suspicion for myotonic dystrophy type I (DM1). DMPK gene repeat analysis was negative (12 CTG repeats in both alleles). Follow-up CNBP gene analysis for myotonic dystrophy type 2 (DM2) was also negative.

The patient's encephalopathy improved with treatment of her pneumonia and avoidance of anesthetics. Her course was complicated by failure to wean from the ventilator, with persistent negative inspiratory forces of -10 to $-15 \mathrm{~cm} \mathrm{H}_{2} \mathrm{O}$, requiring tracheostomy and percutaneous endoscopic gastrostomy (PEG) tube. Additional cardiac evaluations, including MRI and electrophysiologic studies, were negative. An implantable cardiac defibrillator was placed prior to discharge. After 2 months in rehabilitation, she returned home with reversal of her PEG and tracheostomy.

\section{Question for consideration:}

1. Based on the above, what further testing would you consider at follow-up? 


\section{Section 4}

Repeat examination approximately 4 months after initial presentation demonstrated persistent bifacial weakness and ptosis. There was symmetric $4 / 5$ strength of hand intrinsics, ankle dorsiflexors, and plantar flexors. There was $2 / 5$ neck flexor weakness and 4/5 weakness of neck extensors. Percussion myotonia was present in the left thenar eminence. No grip myotonia or warm-up phenomenon was appreciated. Repeat EMG demonstrated recovery of the median and ulnar
CMAPs to 4.2 and $8.0 \mathrm{mV}$, respectively, believed to possibly represent recovery from a prior reversible process such as critical illness myopathy. Electrical myotonia was predominant in distal upper and lower extremity muscles and the sternocleidomastoid. Motor units with short duration, low amplitude, and rapid recruitment were noted in distal upper extremities and sternocleidomastoid. Repeat DMPK testing was sent and the original test company contacted to have the initial study reviewed. Repeat testing demonstrated an allele with 790 CTG repeats. The original test was found to have an

Table Comparison between myotonic dystrophy type 1 (DM1) and myotonic dystrophy type 2 (DM2) 2,3

\begin{tabular}{|c|c|c|}
\hline & DM1 & DM2 \\
\hline \multirow[t]{2}{*}{ Genetics } & AD, CTG repeat of DMPK gene, chromosome $19 q 13.3$ & AD, CCTG repeat of CNBP (ZNF9), chromosome $3 q$ \\
\hline & $\begin{array}{l}\text { Pathologic repeats } \geq 50 \text {, longer repeats correlate with } \\
\text { disease severity }\end{array}$ & $\begin{array}{l}\text { Pathologic repeats } \geq 75 \text {, no correlation between repeat size and } \\
\text { disease severity }\end{array}$ \\
\hline Congenital form? & Yes & No \\
\hline Typical onset & Second-third decade & Third-fourth decade \\
\hline \multirow[t]{3}{*}{ Pattern of weakness } & Distal > proximal in extremities & Proximal > distal (especially in legs) \\
\hline & Early neck flexor involvement & Neck flexor weakness common \\
\hline & Facial weakness common & Facial weakness uncommon \\
\hline Atrophy typical? & Yes & No, may see calf hypertrophy \\
\hline Reflexes & Hypoactive or absent & Normal to brisk \\
\hline \multirow[t]{2}{*}{ Clinical myotonia } & Grip + percussion myotonia common & Mild to absent grip myotonia \\
\hline & "Warm-up” phenomenon & Percussion myotonia uncommon \\
\hline Cataracts? & Yes (prior to age 50, posterior iridescent cataracts) & Yes (prior to age 50, posterior iridescent cataracts) \\
\hline \multirow[t]{3}{*}{ Cardiac involvement } & Occurs in majority, especially adult onset & Conduction defects occur but less common and less severe \\
\hline & $90 \%$ with conduction defects (typically AV or BBB) & Need for pacemaker is variable \\
\hline & Pacemaker recommended if older than 40 & Lower incidence of cardiomyopathy \\
\hline \multirow{3}{*}{$\begin{array}{l}\text { Respiratory } \\
\text { involvement }\end{array}$} & Frequent, require PFT monitoring & Less frequent/severe pulmonary involvement \\
\hline & High incidence of OSA & Lower incidence of OSA \\
\hline & Excessive daytime sleepiness common & Excessive daytime sleepiness less common \\
\hline \multirow{2}{*}{$\begin{array}{l}\text { Gastrointestinal } \\
\text { involvement }\end{array}$} & Dysphagia common & Dysphagia uncommon \\
\hline & GI hypomobility common & GI hypomobility not described \\
\hline \multirow[t]{2}{*}{ Endocrine involvement } & Hypothyroidism common & Hypothyroidism common \\
\hline & Low testosterone/azoospermia common & Low testosterone/azoospermia common \\
\hline \multirow{2}{*}{$\begin{array}{l}\text { Neuropsychiatric } \\
\text { findings }\end{array}$} & Apathy and passive personality traits & Less severe than DM1 \\
\hline & Avoidant/obsessive features described & May be avoidant or obsessive, less often passive \\
\hline \multirow[t]{2}{*}{ EMG findings } & Myotonia present, typically classic "waxing-waning" type & $\begin{array}{l}\text { Myotonia present but less severe, typically more "waning" in } \\
\text { character }\end{array}$ \\
\hline & More prominent in distal UE/LE & $\begin{array}{l}\text { More predominant in distal UE/LE; however, more severe in } \\
\text { proximal LE }\end{array}$ \\
\hline
\end{tabular}

Abbreviations: $\mathrm{AD}$ = autosomal dominant; $\mathrm{AV}$ = atrioventricular; $\mathrm{BBB}=$ bundle branch block; $\mathrm{Gl}$ = gastrointestinal; $\mathrm{LE}$ = lower extremity; $\mathrm{UE}$ = upper extremity. 
allele that was inconclusive and further analysis (Southern blot) demonstrated between 800 and 1,300 CTG repeats.

\section{Discussion}

DM1 is the most common muscular dystrophy of adulthood, which affects 1 per 8,000-9,000 individuals worldwide. Presentations include lethal prenatal disease to incidental discovery beyond the sixth decade. Most commonly, it presents between the second and third decades. While named for the neuromuscular manifestations of myotonia and skeletal muscle disease, the systemic nature of the disorder raises the possibility that a non-neurologist physician may be the first to evaluate these patients. ${ }^{2,3}$

DM1 can be distinguished from DM2 clinically due to pattern of weakness in DM1 involving the face and distal extremities with associated atrophy (table). DM2 typically involves proximal extremities with normal bulk. ${ }^{2}$ DM1 demonstrates more electrical myotonia (EM) than DM2. ${ }^{4}$ The EM is the result of decreased expression of muscle-specific chloride channel type 1 due to abnormal RNA processing from toxic gain of function of transcribed DMPK repeat protein. ${ }^{5}$ This results in membrane hyperexcitability, which can be curtailed by altering sodium channel opening frequency or duration, which is the basis for mexiletine therapy for myotonia. ${ }^{6}$ Our patient's lack of EM initially may be explained by acute effects of amiodarone (shown to have Class IB antiarrhythmic properties acutely) vs her critical illness. ${ }^{7}$

The genetic mutation in DM1 is a CTG repeat in the $3^{\prime}$ untranslated region of the DMPK gene with 34 or less repeats being normal and greater than 50 being diagnostic. While genetic testing has a low false-negative rate, $3 \%-5 \%$ of the DM1 population can have interrupting CCG, CTC, and CGG repeats within the CTG repeat, leading to false-negatives. ${ }^{8}$ Another confounder, especially in critical care settings, is dilution of the tested sample. Average ECMO patients require 2 to 3 packed red blood cells and up to 14 plasma units and cryoprecipitate daily which, in our patient, obscured her initial serum genetic testing. ${ }^{9}$

Patients with DM1 have a hypersensitivity to anesthetic agents and a propensity for prolonged mechanical ventilation. This, in addition to a possible critical illness myopathy, likely contributed to our patient's initial presentation and prolonged hospital course. ${ }^{10}$ While not clinically indicated, muscle biopsy could have helped confirm the patient's possible critical illness myopathy.
This case reaffirms the importance of recognition of the stigmata of DM1. Neurologists should readily recognize and confirm this condition to facilitate rapid referral to a cardiologist to prevent life-threatening arrhythmias and cardiac complications. Genetic testing can confirm the diagnosis; however, neurologists should be aware of potential false-negatives to avoid abandoning the correct diagnosis.

\section{Author contributions}

Timothy Fullam acquired, analyzed, and drafted the content of this clinical reasoning case, including medical writing. John H. Sladky revised the manuscript for content and provided supervision of this clinical reasoning case.

\section{Study funding}

No targeted funding reported.

\section{Disclosure}

The authors report no disclosures relevant to the manuscript. Go to Neurology.org/N for full disclosures.

\section{Disclaimer}

The views expressed in this article are those of the authors and should not be construed to represent those of the US Government, the US Department of Defense, or the US Department of the Army.

\section{References}

1. Preston DC, Shapiro BE. Proximal, distal, generalized weakness. In: Daroff RBJ J, Mazziotta JC, Pomeroy SL, eds. Bradley's Neurology in Clinical Practice, vol 1, 7th ed. Elsevier; 2016:279-295-50.

2. Sansone VA. The dystrophic and nondystrophic myotonias. Continuum 2016;22: 1889-1915.

3. Sommerville RB, Vincenti MG, Winborn K, et al. Diagnosis and management of adult hereditary cardio-neuromuscular disorders: a model for the multidisciplinary care of complex genetic disorders. Trends Cardiovasc Med 2017;27:51-58

4. Logigian EL, Ciafaloni E, Quinn LC, et al. Severity, type, and distribution of myotonic discharges are different in type 1 and type 2 myotonic dystrophy. Muscle Nerve 2007; 35:479-485.

5. Charlet-B N, Savkur RS, Singh G, Philips AV, Grice EA, Cooper TA. Loss of the muscle-specific chloride channel in type 1 myotonic dystrophy due to misregulated alternative splicing. Mol Cell 2002;2002:45-53.

6. Cleland JC, Griggs RC. Treatment of neuromuscular channelopathies: current concepts and future prospects. Neurotherapeutics 2008;5:607-612.

7. Kodama I, Kamiya K, Toyama J. Cellular electropharmacology of amiodarone. Cardiovasc Res 1997;35:13-29.

8. Santoro M, Masciullo M, Silvestri G, Novelli G, Botta A. Myotonic dystrophy type 1: role of CCG, CTC and CGG interruptions within DMPK alleles in the pathogenesis and molecular diagnosis. Clin Genet 2017;92:355-364.

9. Esper SA, Levy JH, Waters JH, Welsby IJ. Extracorporeal membrane oxygenation in the adult: a review of anticoagulation monitoring and transfusion. Anesth Analg 2014, 118:731-743.

10. Russell SH, Hirsch NP. Anaesthesia and myotonia. Br J Anaesth 1994;72:210-216. 


\title{
Neurology
}

\author{
Clinical Reasoning: Persistent respiratory failure following cardiac arrest \\ Timothy Fullam and John H. Sladky \\ Neurology 2018;90;e2174-e2178 \\ DOI 10.1212/WNL.0000000000005688
}

This information is current as of June 11, 2018

\section{Updated Information \& Services}

References

Subspecialty Collections

Permissions \& Licensing

Reprints including high resolution figures, can be found at: http://n.neurology.org/content/90/24/e2174.full

This article cites 9 articles, 0 of which you can access for free at: http://n.neurology.org/content/90/24/e2174.full\#ref-list-1

This article, along with others on similar topics, appears in the following collection(s):

All Neuromuscular Disease

http://n.neurology.org/cgi/collection/all_neuromuscular_disease Clinical neurology examination

http://n.neurology.org/cgi/collection/clinical_neurology_examination Diagnostic test assessment

http://n.neurology.org/cgi/collection/diagnostic_test_assessment_ EMG

http://n.neurology.org/cgi/collection/emg

Trinucleotide repeat diseases

http://n.neurology.org/cgi/collection/trinucleotide_repeat_diseases

Information about reproducing this article in parts (figures,tables) or in its entirety can be found online at:

http://www.neurology.org/about/about_the_journal\#permissions

Information about ordering reprints can be found online:

http://n.neurology.org/subscribers/advertise

Neurology ${ }^{\circledR}$ is the official journal of the American Academy of Neurology. Published continuously since 1951, it is now a weekly with 48 issues per year. Copyright (O) 2018 American Academy of Neurology. All rights reserved. Print ISSN: 0028-3878. Online ISSN: 1526-632X.

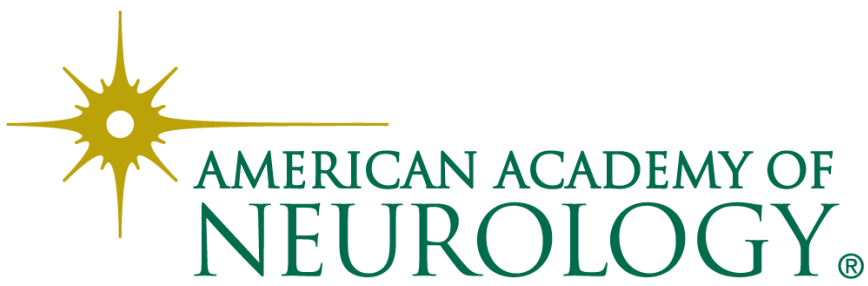

